\title{
SURGERY
}

UDC 616.131-008.331.1: 616.16-002

\section{The pathogenesis of pulmonary hypertension - vessel wall ischemia as the driving force in disease initiation and progression*}

\author{
E. L. Heise ${ }^{1}$, L.P.Churilov ${ }^{2,3}$, T. A. Novitskaya ${ }^{2,3}$, \\ P. K. Yablonsky ${ }^{2,3}$, A. Haverich ${ }^{1}$ \\ ${ }^{1}$ Department of Cardiac, Cardiothoracic, Vascular \\ and Transplantation Surgery, Medizinische Hochschule Hannover, \\ 1, Carl-Neuberg-Str., Hannover, 30625, Germany \\ ${ }^{2}$ St. Petersburg Research Institute of Phthisiopulmonology, \\ Health Ministry of Russia, \\ 2-4, Ligovskiy pr., St. Petersburg, 191036, Russian Federation \\ ${ }^{3}$ St. Petersburg State University, \\ 7-9, Universitetskaya nab., St. Petersburg, 199034, Russian Federation
}

For citation: Heise E. L., Churilov L. P., Novitskaya T. A., Yablonsky P. K., Haverich A. The pathogenesis of pulmonary hypertension - vessel wall ischemia as the driving force in disease initiation and progression. Vestnik of Saint Petersburg University. Medicine, 2021, vol. 16, issue 1, pp. 20-36.

https://doi.org/10.21638/spbu11.2021.103

Surgeons are not trained to decipher the pathogenesis of diseases, which they operate on. They are used to repair, remove, or replace defective tissues and organs. Yet, we often see typical pathomorphological or pathophysiological phenomena, characteristic of a specific disorder that can only be observed during surgery. Such patterns would not be recognized easily by current imaging techniques, and their visibility would require a living organism. In modern terminology, one could call them "surgical biomarkers". Many disease entities, today, are still not completely deciphered regarding initial links of their pathogenesis, despite decades of experimental and clinical research. In such disorders, characteristically named "idiopathic", surgical observations may be helpful to clarify disease mechanisms, two of which we offer here for one of these disease entities, namely pulmonary hypertension.

Keywords: arteria pulmonalis, pulmonary hypertension, vasa vasorum, vasculitis, autoimmunity, atherosclerosis.

* The work of L. P. Churilov and P.K. Yablonsky was supported by the grant of the Russian Federation Government, for state support of the research conducted under the guidance of leading scientists, contract 14.W03.31.0009.

(C) St. Petersburg State University, 2021 


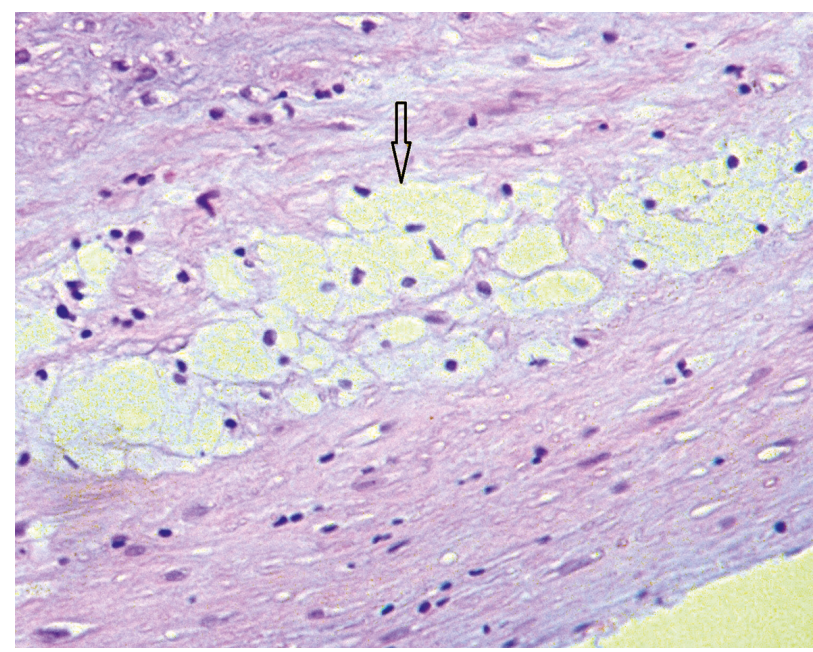

Fig. 1. Foam cells in the intima of small branches of pulmonary arteries in $\mathrm{PH}, \mathrm{H} \& \mathrm{E}, \mathrm{x} 200$

Pulmonary hypertension (PH) equally affects the heart, the lung, including its extrapulmonary great vessels. Cardiothoracic surgeons take care of all three organ systems, in children and adults, opposite to their partners in internal medicine or pediatrics. As the surgical coauthors of this article have repaired, removed, and replaced hearts, lungs and great vessels for many decades, it came to our mind that $\mathrm{PH}$ in its terminal stages exhibits similar patterns of disease as does atherosclerosis. In lung transplantation for $\mathrm{PH}$, we often find macroscopic signs, characteristic for atherosclerosis, e. g. foam cells with lipid deposits, wall thickening, endo-luminal thrombosis, calcific plaques, as well as aneurysm formation, which perfectly correspond to severe atherosclerosis in systemic arteries (Fig. 1).

A second observation regards the increase in collateral circulation beyond arterial obstructions. In the coronary circulation of the heart, we know adventitial vasa vasorum to sprout new arteries in order to bridge an occluded segment of the artery affected, supplying blood to the lumen distal to the occlusion. When operating on acute coronary syndromes or in acute aortic dissections, an impressively increased vascularization can be seen in the adventitial layer of the respective artery, confined to the site of the culprit lesion and mimicking acute localized inflammation. Upon distal incision into the affected artery, tremendous amounts of retrograde blood flow occur, especially in cases with chronic, complete occlusion. The same finding can be made in $\mathrm{PH}$, especially in long-standing, chronic disease. In the lung, vasa vasorum originate from the bronchial arteries [1-3], and their tremendous increase in number and size during progression of $\mathrm{PH}$ to stages, where surgery is required, results in high amounts of back flow from this collateral circulation.

Thus, for the lung transplant surgeon, two characteristic patterns would suggest a comparable disease mechanism in $\mathrm{PH}$ and in atherosclerosis of systemic arteries, the macroscopic phenotype of vessel wall changes and the rich collateral circulation from adventitial vasa vasorum.

A corresponding mechanism between atherosclerosis and $\mathrm{PH}$ is also suggested from the significant number of clinical disorders, where these pathologic findings occur simultaneously in the pulmonary arteries and in large systemic arteries. Among others, this can 
be found in sleep apnea and sickle cell anemia, in Behçet disease, Takayashu arteritis (both being autoimmune entities) and in HIV patients, or in systemic autoimmune inflammatory disorders, e. g. scleroderma and lupus [4-6]. Similar bioregulators (e. g. platelet autacoids) are involved in pathogenesis of all these entities [7].

But why is the pathogenesis of $\mathrm{PH}$ important in surgery? A major issue here is the bronchial circulation, which can complicate surgery on the lung in an important fashion.

\section{Bronchial arteries in thoracic surgery}

$\mathrm{PH}$ represents a family of disease entities of which every lung transplant surgeon develops mixed feelings with growing experience. Postoperatively, perfusion of the bronchial mucosa is compromised at the donor side of the airway anastomosis, since blood supply to this segment of the bronchus is secured via collateral flow from the lung parenchyma, only.

Thus, in the early days of lung transplantation, when unilateral replacement was favored, nearly all patients died postoperatively from dehiscence of this suture line. The initially applied immunosuppressive regimen - copied from renal transplantation at that time - did reduce the healing properties of this anastomosis to an unacceptable degree. Based on the dismal clinical results of these procedures, nearly all clinical programs were discontinued in the late 1970s. Only a few years later, though, lung transplantation for $\mathrm{PH}$ as the underlying disease paved the way to clinical success. Based on the poor results after replacing isolated lungs in infectious disease or chronic obstructive pulmonary disease (COPD), Norman Edward Shumway (1923-2006) and his team at Stanford University focused on $\mathrm{PH}$, thus excluding gross infection of the airway by the nature of the disease. They also focused on combined heart and lung transplantation, which includes an airway anastomosis at the tracheal level, where bronchial artery supply via the coronary arteries is commonly preserved. Thus, selection of patients (with $\mathrm{PH}$ ) and type of surgical procedure allowed for the first successful clinical lung transplant procedures. Only later, immunosuppressive protocols became available that would allow for adequate healing of the bronchial anastomoses in isolated lung transplants, as well. In terms of healing of the bronchial anastomosis, the bronchial circulation comes as a friend to the surgeon.

But it can also be a foe. In patients with $\mathrm{PH}$, bronchial collateral circulation may develop to an extend, where surgical bleeding control becomes impossible. Due to the high number of very thin-walled collateral vessels, mostly originating from the descending thoracic aorta in humans, they may even represent a contraindication to lung transplantation. Additionally, when transplanting lungs for pulmonary vascular disease in a bilateral sequential fashion without the heart, the surgeon has to take special care with respect to the commonly hypertrophied right ventricle, but also regarding the left heart. The left ventricle often presents preoperatively with a restrictive pathogenesis and very small diameters due to long-standing low cardiac output.

For many years, therefore, isolated lung transplantations in subjects with severe pulmonary vascular disease of any type exhibited far less positive results compared to procedures performed in parenchymal lung disease. Today, extracorporeal circulation is commonly installed during surgery for right ventricular protection, and extracor- 
poreal membrane oxygenation (ECMO) support may be required for some days after the procedure to allow the left ventricle for adaptation to higher cardiac outputs. Thus, technically, lung transplantation for $\mathrm{PH}$ remains a very demanding procedure for its perioperative management, but recently, with the precautions taken, results have been comparable to those for other indications [8]. Yet, bleeding from high-flow bronchial arteries, surgically called "collateral circulation" during surgery on one side, and poor collateral flow to the donor bronchus after surgery remain complications that need to be avoided. These "vasa privata", to use an old, but more precise name for bronchial arteries, are definitely structures representing rather foe than friend for the lung transplant surgeon.

The same is true in surgery for chronic pulmonary thromboembolic disease, representing a second surgical disease within disorders characterized by $\mathrm{PH}$. Compared to resection procedures on the lung parenchyma, again a higher surgical risk is seen in pulmonary thromb-endarterectomies, where use of extracorporeal circulation is mandatory. In addition, complete arrest of the circulation, including flow from the heart lung machine, has to be installed with the patient cooled to a body temperature of below $26^{\circ} \mathrm{C}$. Otherwise, the tremendous amount of retrograde blood flow from the bronchial circulation would obscure the operative field, and a precise endarterectomy down to the level of segmental arteries would not be possible.

Next to the poor healing of bronchial anastomoses during transplantation based on bronchial artery transection and the massive retrograde flow in pulmonary end-arterectomies, bronchial arteries represent a threat to thoracic surgeons in a third pathophysiologic condition. This is $\mathrm{PH}$ in subjects presenting with a history of previous surgical interventions in the chest. In addition to massively enlarged bronchial arteries in the hilum of the lung, in such cases multiple, thin-walled arteries from the systemic circulation may have developed across adhesions between the visceral and the parietal pleural layers. After experimental ligation of the pulmonary artery in mice, which lack a bronchial circulation, large areas of the inner chest wall are seeded with blood vessels [9].

These collateral vessels from the intercostal arteries grow between the two pleural layers to deliver oxygen to the ischemic lung. Macroscopically, their appearance resembles "plexiform lesions" within the parenchyma of lungs in $\mathrm{PH}$. In humans, their presence remains a contraindication to lung transplantation, still today, since many patients have bled to death from such collaterals during explantation of their own lungs in the past. The memories of such situations from the early times of combined heart and lung transplantation will be on the surgeon's mind for a life-time.

Thus, hyperperfusion of the lung via the bronchial circulation, by surgical experience, reflects a unifying characteristic in all types of $\mathrm{PH}$ (see: table 1 below), as defined by a recent WHO classification [4]. This includes - yet to a lesser degree - secondary types of $\mathrm{PH}$ as seen in terminal stages of lung fibrosis, COPD, or generalized inflammatory diseases also affecting the pulmonary circulation, e. g. systemic sclerosis. This "surgical biomarker" would represent a further characteristic when looking at similar features in $\mathrm{PH}$ and atherosclerosis in systemic arteries. This is especially true, since we know that bronchial arteries do supply the rich network of vasa vasorum in the adventitial layer of the pulmonary artery walls $[1 ; 10]$, which seem to play an important role in vascular remodeling of these vessels in $\mathrm{PH}$ [11], as do adventitial vasa vasorum in atherosclerosis development in systemic arteries [12]. 


\section{Pulmonary arterial hypertension}

1.1. Idiopathic $\mathrm{PAH}$

1.2. Heritable PAH

1.2.1. BMPR2

1.2.2. ALK-1, ENG, SMAD9, CAV1, KCNK3

1.2.3. Unknown

1.3. Drug and toxine induced

1.4. Associated with:

1.4.1. Connective tissue disease

1.4.2. HIV-Infection

1.4.3. Portal Hypertension

1.4.4. Schistosomiasis

1.5. Persistent pulmonary hypertension of the newborn

Pulmonary venooclusive disease (PVOD) / pulmonary capillary hemangiomatosis

\section{Pulmonary hypertension due to left heart disease}

2.1. Left ventricular systolic dysfunction

2.2. Left ventricular diastolic dysfunction

2.3. Valvular disease

2.4. Congenital / aquired left heart inflow / outflow tract obstruction and congenital cardiomyopathies

\section{Pulmonary hypertension due to lung disease and/or hypoxia}

3.1. Chronic obstructive pulmonary disease

3.2. Intestinal lung disease

3.3. Other pulmonary disease with mixed restrictive and obstructive pattern

3.4. Sleep-disordered breathing

3.5. Alveolar hypoventilation disorders

3.6. Chronic exposure to high altitude

3.7. Developmental lung diseases

\section{Chronic thromboembolic pulmonary hypertension (CTEPH)}

\section{Pulmonary hypertension with unclear multifactorial mechanisms}

5.1. Hematologic disorders: chronic hemolytic anemia, myeloproliferative disorders, splenectomy

5.2. Systemic disorders: sarcoidosis, pulmonary histiocytosis, lymphangioleiomyomatosis

5.3. Metabolic disorders: glycogen storage disease, Gaucher disease, thyroid disorders

5.4. Others: tumoral obstruction, fibrosing mediastinitis, chronic renal failure, segmental $\mathrm{PH}$

${ }^{*} 5^{\text {th }}$ WSPH Nice 2013

${ }^{\star *} \mathrm{BMPR}=$ Bone morphogenic protein receptor type II; CAV1 = caveolin-1; ENG = endoglin

\section{Remodeling of pulmonary arteries}

During surgery, $\mathrm{PH}$ cases with chronic pulmonary embolism can be easily distinguished from other $\mathrm{PH}$ patients. Here, the typical features of wall thickening, arterial distension and intimal thrombus formation stops at the level of segmental arteries in most cases. Surgical removal by thromb-endarterectomy can actually cure the disease without organ replacement, a singular phenomenon looking at the entire spectrum of terminal $\mathrm{PH}$. All other entities presenting with $\mathrm{PH}$ are progressive in nature, not accessible to conventional surgery, and incurable by known medical treatment. Thus, only transplantation can assure medium to long-term survival. In these cases, the disease increases in sever- 
ity from central pulmonary arteries towards their peripheral, intrapulmonary branches, which is especially true with regard to wall thickening and luminal thrombosis. Here, the main pulmonary arteries are often free from thrombosis, yet, a severe increase of wall thickness and luminal diameters are present, sometimes triple the dimensions of the donor pulmonary artery in transplantation. Four years ago, the author of this communication $(\mathrm{AH})$ contributed "Key role of vasa vasorum dysfunction in the pathogenesis of atherosclerosis" [14].

In above mentioned article we focused on the role of the adventitial layer on the pathobiology of atherosclerotic remodeling processes in systemic arteries, putting emphasis especially on the role of the vasa vasorum in the nutrition of the vascular wall. Many surgical observations were outlined, supporting the concept. Like for the pathogenesis of atherosclerosis, a number of differing concepts have been proposed regarding disease initiation and progression in PH. None of them, as written in a recent review article [14] would be able to explain the disease process in a comprehensive fashion.

Again based on surgical observations, and again describing the unique pathophysiology of vessel wall nutrition via the vasa vasorum in the small pulmonary arteries involved in the disease, a similar, comprehensive concept is proposed here.

In describing the pathophysiological process of vascular remodeling in pulmonary arteries during disease initiation and progression in $\mathrm{PH}$, this concept would also highlight blood vessel wall ischemia as the driving force of vascular remodeling, in line with the previous description of the pathophysiology of atherosclerosis of systemic arteries. An important question here would be, if the histologic pattern of disease within the small pulmonary arteries in $\mathrm{PH}$ does support the hypothesis (Table 2).

\section{Vasa vasorum and vessel wall ischemia}

In systemic arteries, vasa vasorum commonly originate from their parent vessel at sites of branching. As mentioned before, vasa vasorum of pulmomary arteries originate from bronchial arteries. Like in systemic arteries, therefore, oxygenated blood from the systemic circulation is provided via the adventitial layer to the wall of pulmonary vessels, as well. Offspring from the parent vessel would not be efficient, here, since the arteries in the lung, of course, transport de-oxygenated blood. In consequence, a fundamental anatomical difference exists between the systemic and the pulmonary artery tree with regard to distribution of their vasa vasorum. In the systemic circulation, only large and mediumsized vessels carry vasa vasorum [15-17], since the thinner walled smaller arteries are supplied with nutrients and oxygen by diffusion from the lumen alone. As a consequence of the low oxygen content of the blood in lung arteries, even the small, pre-capillary arteries at external diameters equal or below 200 micrometer are dependent on external blood supply via vasa vasorum, since oxygen supply via their lumen would be insufficient [18; 19]. This finds especially true, because these vessels present with a highly muscularized medial layer [20; 21], known to require high rates of oxygen supply. In consequence, and opposite to systemic arteries, vessel wall ischemia from disturbed or insufficient microcirculation via their vasa vasorum may occur in the small, precapillary, muscular arteries in the lung, as well. To our knowledge, this unique physiologic-anatomical difference between the systemic and the pulmonary circulation (Fig. 2) has not been appreciated in the literature, so far, although existence of vasa vasorum in adventitia of small extrahilar 
Table 2. Pathomorphological findings of pulmonary and systemic arteries in atherosclerosis

\begin{tabular}{|c|c|c|c|c|}
\hline & Intima & Media & Adventitia & $\begin{array}{l}\text { Perivascular } \\
\text { Lymphatics }\end{array}$ \\
\hline PAH & $\begin{array}{l}\text { - Fraying of the elastic } \\
\text { membrane } \\
\text { - Connective tissue } \\
\text { widening and } \\
\text { remodeling of the } \\
\text { intima } \\
\text { - Disordered } \\
\text { proliferation of } \\
\text { subendothelial } \\
\text { mesenchymal cells } \\
\text { - Concentric, onion- } \\
\text { skin-like fibrosis } \\
\text { - Disfunction of } \\
\text { the pulmonary } \\
\text { endothelium }\end{array}$ & $\begin{array}{l}\text { - Initial hypertrophy } \\
\text { of the media } \\
\text { - Smooth muscle } \\
\text { cell proliferation } \\
\text { and progressive } \\
\text { accumulation } \\
\text { of adventitial } \\
\text { fibroblasts } \\
\text { - Distal } \\
\text { muscularization } \\
\text { of previously non- } \\
\text { muscularized small } \\
\text { pulmonary arteries }\end{array}$ & $\begin{array}{l}\text { Adventitial } \\
\text { thickness increases } \\
\text { predominantly due to } \\
\text { collagen deposition }\end{array}$ & $\begin{array}{l}\text { Delicate network of } \\
\text { lymphatic vessels, } \\
\text { often close to } \\
\text { plexiform lesions } \\
\text { Bronchus-associated } \\
\text { lymphoid tissue } \\
\text { expands in pulmonary } \\
\text { hypertension and is } \\
\text { autoimmunologically } \\
\text { active }\end{array}$ \\
\hline $\begin{array}{l}\text { Athero- } \\
\text { sclerosis }\end{array}$ & $\begin{array}{l}\text { Intima thickening: } \\
\text { Accumulation of } \\
\text { smooth muscle cells } \\
\text { within a matrix of } \\
\text { proteoglycans } \\
\text { Lipid-rich necrotic } \\
\text { cores in the central } \\
\text { part of the intima } \\
\text { Fibrous tissue form a } \\
\text { fibrotic cap to cover } \\
\text { the necrotic cores } \\
\text { Elastic fibers may be } \\
\text { split or frayed }\end{array}$ & \begin{tabular}{|l} 
Vascular smooth \\
muscle cell \\
proliferation in \\
atherosclerosis appears \\
to be predominantly \\
reparative, even in \\
atherogenesis, and not \\
the primary driver of \\
plaque formation. \\
\\
Decrease in the \\
number of smooth \\
muscle cells in the \\
tunica media in \\
atherosclerotic plaques
\end{tabular} & $\begin{array}{l}\text { Pathological } \\
\text { angiogenesis of the } \\
\text { vessel wall } \\
\text { Cells that appear to be } \\
\text { lymphocytes can be } \\
\text { adjacent to adventitial } \\
\text { vasa vasorum }\end{array}$ & $\begin{array}{l}\text { Lymphatic } \\
\text { microvessels are } \\
\text { often present in } \\
\text { atherosclerotic vessels } \\
\text { Lymphocytes, } \\
\text { monocyte- } \\
\text { macrophages, } \\
\text { and plasma cells } \\
\text { are frequently } \\
\text { associated with } \\
\text { the capillaries, and } \\
\text { microhemorrhages } \\
\text { may be present around } \\
\text { them. } \\
\text { Vascular-associated } \\
\text { lymphoid tissue } \\
\text { (VALT) or arterial } \\
\text { lymphoid organ } \\
\text { (ATLO) adjacent to } \\
\text { the diseased tissue in } \\
\text { arteries }\end{array}$ \\
\hline
\end{tabular}




\begin{tabular}{|c|c|c|c|c|}
\hline $\begin{array}{c}\text { (Fibrinoid) } \\
\text { necrosis vessel wall }\end{array}$ & Lumen & $\begin{array}{l}\text { Microvessel } \\
\text { proliferation }\end{array}$ & Micro-hemorrhage & $\begin{array}{l}\text { Endothelial- } \\
\text { mesenchymal } \\
\text { transition } \\
(\text { EndMT) }\end{array}$ \\
\hline $\begin{array}{l}\text { Necrotizing arteritis } \\
\text { of smaller arteries } \\
\text { can be a present } \\
\text { feature in PAH }\end{array}$ & $\begin{array}{l}\text { Obliteration of the } \\
\text { vessel lumen }\end{array}$ & $\begin{array}{l}\text { Plexifom lesions: } \\
\text { spherical complex } \\
\text { proliferates of } \\
\text { endothelial lined } \\
\text { blood channels, } \\
\text { which are } \\
\text { conncted through } \\
\text { a homogeneous } \\
\text { smooth-muscular } \\
\text { interstitium }\end{array}$ & $\begin{array}{l}\text { Hemosiderin-laden } \\
\text { perivascular } \\
\text { macrophages } \\
\text { as a correlate of } \\
\text { hemorrhages that } \\
\text { have taken place }\end{array}$ & $\begin{array}{l}\text { EndMT is } \\
\text { involved in the } \\
\text { occlusive vascular } \\
\text { remodeling of } \mathrm{PAH}\end{array}$ \\
\hline $\begin{array}{l}\text { These include the } \\
\text { following: the } \\
\text { nature of fibrinoid } \\
\text { necrosis and the } \\
\text { susceptibility of } \\
\text { small brain arteries } \\
\text { and arterioles to } \\
\text { this lesion even in } \\
\text { the so-called benign } \\
\text { hypertension }\end{array}$ & $\begin{array}{l}\text { Obliteration of the } \\
\text { vessel lumen }\end{array}$ & $\begin{array}{l}\text { Angiogenic } \\
\text { microvessels } \\
\text { penetrate and } \\
\text { expand into the } \\
\text { media and plaque } \\
\text { of advanced lesions }\end{array}$ & $\begin{array}{l}\text { Leakiness of newly } \\
\text { formed vessels } \\
\text { may produce } \\
\text { hemmorrhage } \\
\text { within the arterial } \\
\text { wall, provoking an } \\
\text { increase of fibrous } \\
\text { tissue }\end{array}$ & $\begin{array}{l}\text { EndMT-derived } \\
\text { cells comprised } \\
\text { almost one-half } \\
\text { of the fibroblast } \\
\text { population } \\
\text { in advanced } \\
\text { atherosclerotic } \\
\text { lesions } \\
\text { EndMT-derived } \\
\text { fibroblast-like cells } \\
\text { make a significant } \\
\text { contribution to } \\
\text { atherosclerotic } \\
\text { plaques }\end{array}$ \\
\hline
\end{tabular}




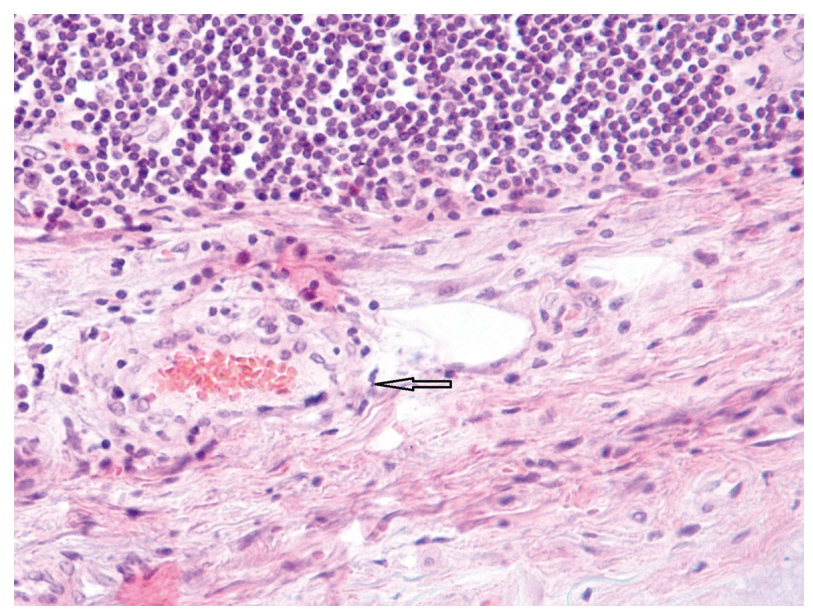

Fig. 2. Vasa vasorum in adventitia of small branches of pulmonary arteries, $\mathrm{H} \& \mathrm{E}, \mathrm{x} 200$

branches of pulmonary arteries has been shown as early as in 1964, when they were revealed in all branches with $\geq 1 \mathrm{~mm}$ of diameter [22].

In systemic arteries, the oxygen demand of their vessel wall increases with growth during childhood and adolescence, when the blood pressure increases and higher wall tension requires an increase in wall thickness. The anatomic response to this physiologic phenomenon is the establishment of a microcirculation within the blood vessel wall, originating from adventitial vasa vasorum, which are practically absent in arteries in the newborn.

Similarly proceeds the ontogenesis of vasa vasorum in human pulmonary arteries: they penetrated the outer third of the media in pulmonary trunk starting from fourth year, and in the distal part of extrahilar pulmonary arterial bed - from tenth year of postnatal life [23].

But, only those arteries can develop atherosclerosis, where vasa vasorum are present [24], and in children, Kawasaki disease (an autoimmune entity) remains confined to aortic and coronary artery segments, where vasa vasorum have been developed [25], already.

Postulating the disturbed microcirculation of the small pulmonary arteries to represent the initiating factor to precipitate $\mathrm{PH}$, we could see two distinct pathophysiological mechanisms to be involved in the initial phase of the disease: the increase in oxygen demand or a decreased supply via arterial vasa vasorum. Thus, an imbalance between oxygen demand and supply in the wall of pulmonary arteries has to be operative, if the histo-pathologic pattern in $\mathrm{PH}$ would result from an analogous mechanism as the atherosclerosis in systemic arteries.

There are two types of $\mathrm{PH}$, where a discrepancy between oxygen demand and supply would occur from increased demand (Fig. 3).

1. Eisenmenger's syndrome represents one disorder reflecting a pathophysiological situation, where oxygen demand increases with growth of vessel wall thickness. High shear stress from increased pulmonary blood flow does results from congenital heart disorders including large left to right shunts on the atrial or on the ven- 


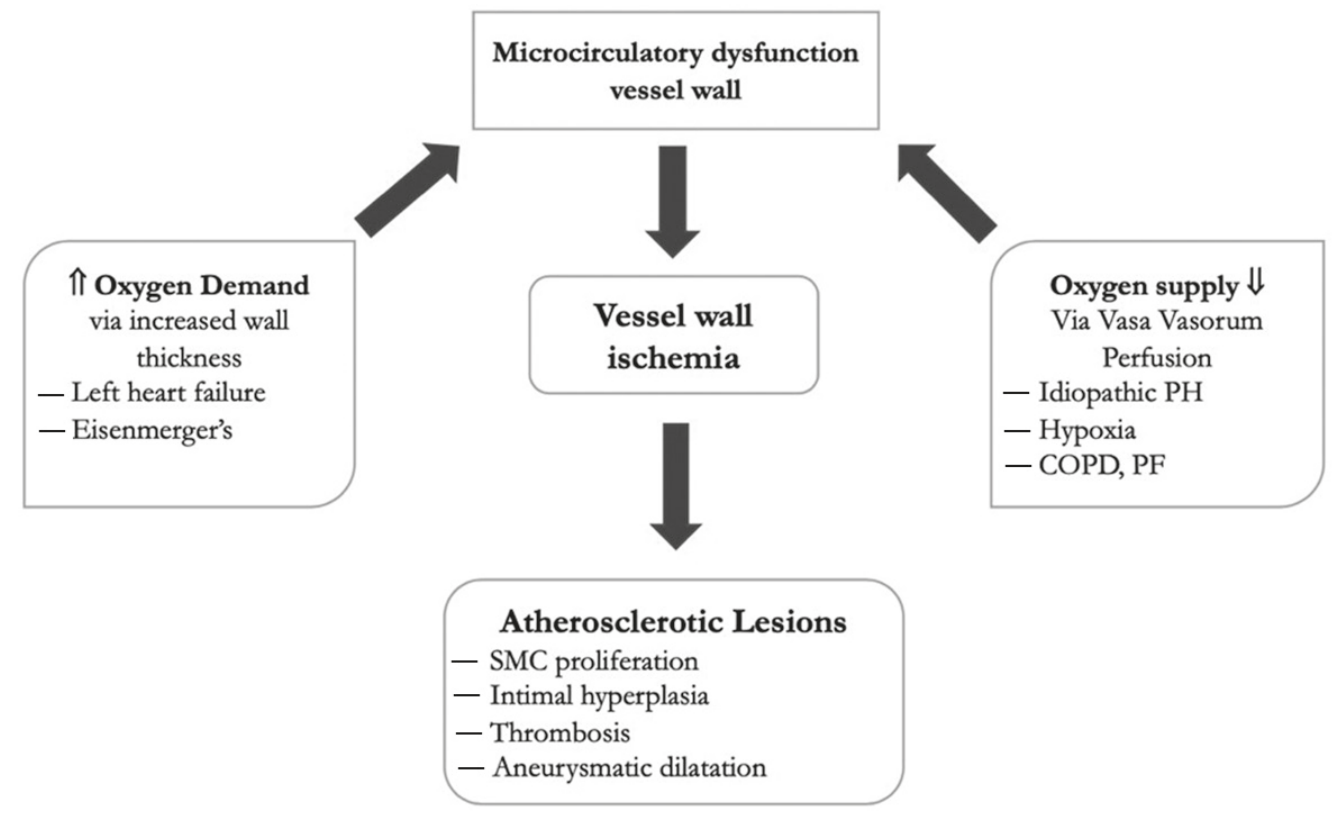

Fig. 3. Pathophysiologial conditions resulting in pulmonary artery wall ischemia and subsequent $\mathrm{PH}$

tricular level. After years to decades, the resulting hypertrophy of the vessel wall in small, precapillary pulmonary arteries requires a substantially increased blood supply. If this can no longer be compensated by an increased vascularization via adventitial vasa vasorum, ischemia of the vessel wall results in histologic changes, the stages of which have been well described earlier [26].

2. The most common type of $\mathrm{PH}$ results from left heart failure, resulting in increased pulmonary venous pressures. In order to maintain an adequate perfusion pressure within the pulmonary capillary bed, pulmonary artery pressure has to increase, accordingly [26]. As a result, wall thickness increases, as does oxygen demand, comparable to systemic arteries during growth of an individual. In consequence, ischemia of the wall in pulmonary arteries, small and large, would result, if de novo sprouting of adventitial vasa vasorum becomes insufficient.

These subtypes of $\mathrm{PH}$ would represent disorders, where increase in vessel wall thickness of small and large pulmonary arteries results in an increased oxygen demand (Fig. 2). The other types of $\mathrm{PH}$ are characterized by a more peripheral initial affection of the pulmonary arterial bed, initially. Here, a decrease in vasa vasorum perfusion and subsequent ischemia of the vessel wall from decreased oxygen supply is proposed to represent the key factor in the pathogenesis of $\mathrm{PH}$.

Hypoventilation of pulmonary alveoli (brought in by any reason) causes alveolar hypoxia, which automatically provokes vasoconstriction at the zone of poorly ventilated alveoli. This phenomenon historically was known as von Euler - Lillestrand "reflex" [27]. In fact the phenomenon discovered by these Swedish scholars later appeared to be of non-neural origin, because both ganglion blockers and lung denervation were unable to prevent it. Nevertheless, this is extremely important mechanism redistributing the blood 
supply in favor of well-ventilated lung portions in order to maintain ventilation / perfusion $(\mathrm{V} / \mathrm{P})$ matching [28]. Although it is very useful for optimization of regional V/P ratio, it should not disturb topical variance of this parameter through the lungs. It can be detrimental if violates the topical regional border and involves both lungs in global hypoxia, for example, in high altitude disease or in pulmonary heart disease. In such cases it provokes generalized vasoconstriction in lesser circulation, thus causing PH.

That is a bright example of the general pathology principle earlier coined by L. P. Churilov [29] and stating that the balance of local and systemic defensive mechanisms is health prerequisite, but their conflict due to trespassing the borders normally limiting their spheres of action is always highly pathogenic.

The very mechanism of the hypoxic pulmonary vasoconstriction is still disputable, and there are several theories for its explanation, based on quite remarkable research achievements of late $20^{\text {th }}$ century. There are hypoxia-sensitive voltage-gated potassium channels in pulmonary artery smooth muscle cells, which cause their depolarization in response to low local pO2, with activation of calcium influx and vascular spasm [30]. Also, transient receptor potential canonical 6 (TRPC6) and vanilloid 4 (TRPV4) channels are involved in such direct reaction probably driven by local autacoids [31].

Moreover, there is an assumption that some electrical signal generated in capillary endothelial cells of lesser circulation is transmitted via intercellular gaps upstream towards the arteriole smooth muscle cells, thus representing non-neural "electric wire" and resulting in local spasm of arterioles. The antagonists of gap junction connexin- 40 protein can stop this process and attenuate hypoxic vasoconstriction phenomenon [32].

It is obvious that disorder of vasa vasorum function similar to that observed in atherosclerosis can trigger all the above-mentioned mechanisms and establish $\mathrm{PH}$ via mechanisms involved in von Euler - Lillestrand phenomenon. "The end result of the above mechanisms is increased pulmonary arterial pressure and resistance" [33].

Hypoxic pulmonary vasoconstriction (HPV) appears to represent a key mechanism in the initial phase of these $\mathrm{PH}$ types. Its regional activation in cases with local alveolar hypoxia, e. g. in atelectasis, pneumonia, or COPD, exerts a beneficial effect on the systemic oxygen delivery in that intrapulmonary perfusion is matched to regional ventilation. This is a defensive role of vasoconstriction in the small pulmonary arteries in areas with alveolar hypoxia, which, as mentioned above, is known since 1946 [27; 34; 35].

But, it is worth to emphasize again that in global alveolar hypoxia, this response might occur throughout the entire pulmonary circulation. This has been shown to result in an increased pulmonary artery pressure, which is not the case in regional or focal hypoxic conditions. HPV is actuated via sensing oxygen tension in vascular smooth muscle cells (SMC), located in the medial layer of the pulmonary artery [36]. The circumferential distribution of SMC within the medial layer will result in circumferential vessel wall contraction. Interestingly, this effect uniformly occurs preferably in pre-capillary pulmonary arterioles, immediately proximal to their branching into alveolar capillaries [37]. The phenomenon of disease initiation at branching sites is also known from atherogenesis in systemic arteries [38; 39]. Looking at the potential influence of adventitial vasa vasorum in precipitating vascular contraction, again an analogous phenomenon from systemic arteries may be of importance. The influence of vasa vasorum perfusion has been well demonstrated by surgical removal of the adventitia in the ascending aorta, including the adventitial vasa vasorum [40]. At this anatomic location, loss of the ability to relax, which is 
the energy-consuming action of SMCs, results in immediate loss of the Windkessel effect of the aorta. As a result, an instantaneous increase in systolic, and a decrease in diastolic blood pressure can be observed.

Postulating the same mechanism in HPV, a reduction of flow or in oxygen content in the vasa vasorum of the small pulmonary arteries has to be assumed. As opposed to left heart failure and Eisenmenger's syndrome, where increased vessel wall thickness is present, this effect must be operative in the normal blood vessel wall both in regional and in global HPV. Since the effect occurs in the presence of normoxic arterial blood in the bronchial arteries, flow reduction in the vasa vasorum of affected pre-capillary pulmonary arteries has to be postulated. Intraluminal oxygen pressure is the same in vasoconstricted as well as in normally perfused arteries, thus, here luminal hypoxia cannot play a part.

This mechanism of insufficient perfusion of the arterial wall via their adventitial vasa vasorum would clearly be supported by the histopathologic findings in HPV, but also in other types of $\mathrm{PH}$.

In systemic arteries, no atherosclerosis can be seen in arteries that do not carry vasa vasorum, like the internal thoracic artery or intramural stretches of epicardial coronary arteries. These observations in the systemic circulation clearly underline the importance of vasa vasorum in the pathogenesis of $\mathrm{PH}$, as well. Upon experimental obstruction of adventitial vasa vasorum in the aorta in dogs, pigs and rabbits, early signs of atherosclerosis are visible within several days [41-44]. In other experiments, this intervention could induce formation of arterial aneurysms [40].

All characteristics of early and late changes in HPV (Table 2) are inducible in systemic arteries upon vessel wall ischemia from disruption of flow in adventitial vasa vasorum. These include SMC proliferation, intimal hyperplasia, luminal thrombosis, increase in media thickness, plaque formation and aneurysmatic dilatation. Thus, from both, functional observations (vasoconstriction) and from histopathological findings, disease initiation via malfunctioning adventitial vasa vasorum can be suggested to play a key part in HPV pathogenesis, as well.

Recently S. Umar et al. showed that human PH is associated with decreased low density lipoprotein (LDL) receptor expression in lungs and increased oxidized LDL in lungs and blood plasma. Western diet-fed LDL receptor knockout mice develop PH and right ventricular dysfunction, implicating a role for LDL receptor and oxidized lipids in pathogenesis of PH [45]. But LDL receptor dysfunction as well as oxidized lipids and reactive oxygen species produced in hypoxia - all are key players in atherogenesis also [46-48].

To our opinion, a link which may join together all these facets may be related to autoimmunity.

Autoimmunity is deeply involved in pathogenesis of atherosclerosis at many points [49]. Immunological links of its pathogenesis and immunological approach to its experimental treatment - both are the old but evergreen ideas dated back to pioneering works of 1960s by Hungarian pathologists [50]. Autoantibodies against oxidized low-density lipoproteins (ox-LDL) take part in atherogenesis; moreover, several experimental models of atherosclerosis via passive adoptive T cell transfer and / or immunization with autoantigens such as lipoproteins, $\beta 2$ glycoprotein I ( $\beta 2$-GPI) and heat shock proteins (HSP) - all witness for autoimmune links of atherogenesis [51]. 


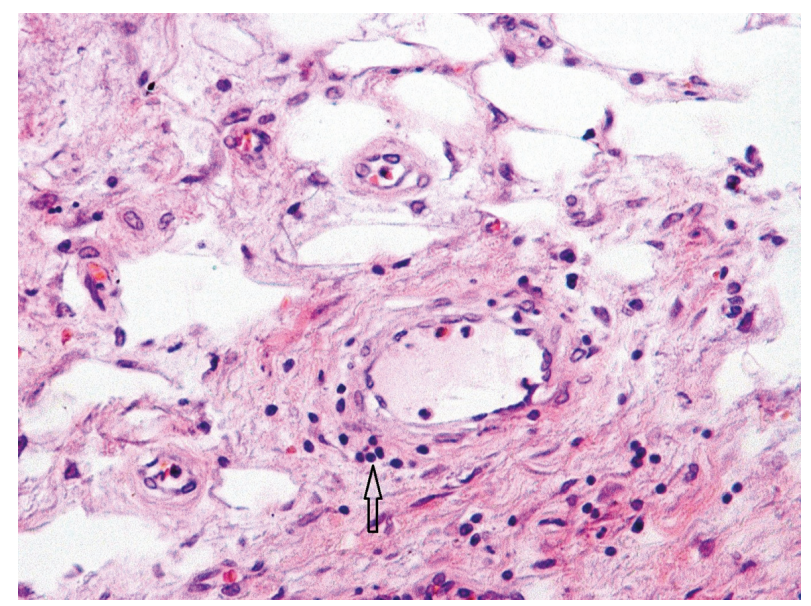

Fig. 4. Focal small lymphoid infiltrates vasa vasorum in adventitia of small branches of pulmonary arteries, H\&E, x 200

The atherogenesis is accelerated in those rheumatic diseases accompanied by autoimmune vasculitides [52]. But $\mathrm{PH}$ also is common in systemic autoimmune diseases proceeding with the immunopathological vasculitides [53]. As early as in 1979 V.P. Gorbachev documented regular typical presence of the immunopathological vasculitis of vasa vasorum in pulmonary arteries of the patients with polyarteritis nodosa, systemic lupus erythematosus, systemic scleroderma, and rheumatoid arthritis [54].

Moreover, recently an autoimmune mouse model of $\mathrm{PH}$ was obtained [55]. These facts and relations make it possible to assume that atherosclerosis and $\mathrm{PH}$, both quite often coinciding [56]. may equally result from autoimmune (immunopathological) vasculitides of vasa vasorum.

Fig. 4 below demonstrates lymphoid infitration of vasa vasorum in adventitia of small branches of pulmonary artery in a case of $\mathrm{PH}$. Similar lymphoid infiltrates are typical for target organs in many autoimmune diseases including some autoimmune vasculitides, hence this pathomorphological observation may confirm hypothesis.

By the way, analogous close correlation of systemic and pulmonary atherosclerosis and hypertensive states has been recently demonstrated in cats in veterinary pathology [57].

In this communication, the pivotal role of vessel wall ischemia within the complex pathobiology of $\mathrm{PH}$ is described as a unifying concept for disease initiation and progression in all types of $\mathrm{PH}$, except those of thromboembolic genesis. No molecular mechanisms are detailed, albeit some of them were mentioned and their understanding would be of significance, especially with regard to potential drug treatment. We believe, though, that the majority of these molecular effects come into play, once ischemia of the vessel wall is initiated.

We provided few pathomorphological vitnesses for the existence of vasa vasorum in small branches of pulmonary arteries, for their involvement in atherosclerosis and in immunopathological processes (Fig. 1-3 above).

Also, additional important histological findings like immunopathological vasculitis of vasa vasorum, perivascular inflammation and adventitial sclerosis, as well as the development of lymphoid infiltration and plexiform lesions are still considered consequences of HPV, but can be among its initiating features. Yet, understanding their mode of genera- 
tion would undoubtedly add to our current understanding of the concerted mechanism in $\mathrm{PH}$ initiation and progression, not the least in regenerative attempts to potentially reverse the disease.

At this point, we propose a unifying mechanism for disease initiation and progression in $\mathrm{PH}$ by a dysfunctional microcirculation of the pulmonary arteries at the arteriolar level. The hypoxic condition could be the result of increasing wall thickness combined with an incomplete response in terms of vascularization in terms of angiogenesis of vasa vasorum, or primary dysfunction of vasa vasorum of pre-capillary pulmonary arteries. Thus we agree with K. J.Dunham-Snary et al., who stated, "Although increased by endothelium-derived vasoconstrictors (e. g., endothelin and thromboxane) and inhibited by endothelium-derived vasodilators (e. g., nitric oxide and prostacyclin), the core effector mechanism of HPV lies within the pulmonary arteries SMC" [26] ... and would add: "and their reaction to a disturbed microcirculation".

For sure, our assumption can be criticized judging upon a puristic standpoint of classical pathology that atherosclerosis starts from intima and spreads towards adventitia and should be strictly distinctive from arteriosclerosis, which, vice versa, takes origin from adventitia spreading inwards to intima [58].

To refute this probable criticism, we have to mention that under the influence of the recent experience of transplantology and vascular surgery old good classification of arteriosclerosis looks more and more inconsistent, and there is a tendency to its re-thinking [59].

And, after all our hypothesis absolutely is not in contradiction with a statement that true atherosclerosis starts from the lesion of endothelium and intima. We just put in the centre of attention endothelial and intimal changes in vasa vasorum under the influence of their (autoimmune / immunopathological?) vasculitis.

This concept leaves many questions unanswered and opens new ones. How does the $\mathrm{HPV}$ mechanism translate into idiopathic $\mathrm{PH}$, where alveolar hypoxia cannot represent the driving force? How does the mechanism acts in a gender - specific manner and in genetically predisposed individuals, like in carriers of BMDR mutation? What is the role of shunting between the bronchial artery system and the pulmonary arteries, and the role of shunting between pulmonary arteries and veins, physiological phenomena, clearly separating pulmonary hemodynamics from the systemic circulation?

Is it possible that autoimmune / immunopathological vasculitis of vasa vasorum as a typical universal mechanism contributes into pathogenesis of several nosologically different and previously not associated cardiovascular disorders, like atherosclerosis, dissecting aneurisms, PH, severe COVID-19 and Kawasaki disease (which idea already has been coines in our recent article)?

These and other related questions will have to be answered to fully elucidate the pathogenesis of $\mathrm{PH}$ in its different categories, hopefully allowing for successful medical treatment instead of organ transplantation, in the future.

Author contributions: A. Haverich - idea, main concept, literature analysis; E. L. Heise - literature analysis, writing; T. A. Novitskaya - pathomorphological studies \& corresponding pictures; L. P. Churilov - autoimmune aspects of the concept, literature analysis, final editing; P. K. Yablonsky - literature analysis, final editing. 


\section{References}

1. Valij K. Vascular and Interventional Radiology. $2^{\text {nd }}$ edition. W. B. Saunders Co. Ltd, 2006.

2. Miller W. S. The Lung. Charles C. Thomas, 1947.

3. Hayek H., von. The Human Lung. Hafner, 1960.

4. Simonneau G., Montani D., Celermajer D. S., Denton C. P., Gatzoulis M. A., Krowka M., Williams P. G., Souza R. Haemodynamic definitions and updated clinical classification of pulmonary hypertension. The European respiratory journal, 2019, vol. 53, no. 1. https://doi.org/10.1183/13993003.01913-2018

5. Mani P., Gonzalez D., Chatterjee S., Faulx M.D. Cardiovascular complications of systemic sclerosis: What to look for. Cleve Clin. J.Med., 2019, vol. 86, no. 10, pp. 685-695. https://doi.org/10.3949/ ccjm.86a.18109

6. Agmon-Levin N., Selmi C. The autoimmune side of heart and lung diseases. Clinical Reviews in Allergy and Immunology, 2013, vol. 44, no. 1, pp. 1-5. https://doi.org/10.1007/s12016012-8335-x

7. Trojanowska M. Role of PDGF in fibrotic diseases and systemic sclerosis. Rheumatology, 2009, vol. 47 (Suppl. 5), pp. 4-6. https://doi.org/10.1093/rheumatology/ken265

8. Salman J, Ius F., Sommer W., Siemeni T., Kuehn C., Avsar M., Boethig D., Molitoris U., Bara C., Gottlieb J., Welte T., Haverich A., Hoeper M. M., Warnecke G., Tudorache I. Mid-term results of bilateral lung transplant with postoperatively extended intraoperative extracorporeal membrane oxygenation for severe pulmonary hypertension. European Journal of Cardio-thoracic Surgery, 2017, vol. 52, no. 1, pp. 163-170. https://doi.org/10.1093/ejcts/ezx047

9. Mitzner W., Lee W., Georgakopolous D., Wagner E. Angiogenesis in the mouse lung. American Journal of Pathology, 2000, vol. 157, no. 1, pp. 93-101. https://doi.org/10.1016/S0002-9440(10)64521-X

10. Walker C. M., Rosado-De-Christenson M.L., Martínez-Jiménez S., Kunin J.R., Wible B. C. Bronchial arteries: Anatomy, function, hypertrophy, and anomalies. Radiographics, 2015, vol. 35, no. 1, pp. 32 49. https://doi.org/10.1148/rg.351140089

11. Humbert M., Guignabert C., Bonnet S., Dorfmüller P., Klinger J. R., Nicolls M. R., Olschewski A. J., Pullamsetti S. S., Schermuly R. T., Stenmark K. R., Rabinovitch M. Pathology and pathobiology of pulmonary hypertension: state of the art and research perspectives. The European respiratory journal, 2019, vol. 53, no. 1. https://doi.org/10.1183/13993003.01887-2018

12. Mulligan-Kehoe M. J., Simons M. Vasa Vasorum in Normal and Diseased Arteries. Circulation, 2014, vol. 129, no. 24, pp. 2557-2566. https://doi.org/10.1161/Circulationaha.113.007189

13. Haverich A., Boyle E. C. Key role of vasa vasorum dysfunction in the pathogenesis of atherosclerosis. Clinical Pathophysiology, 2016, vol. 3, no. 22, pp. 88-96.

14. Bordenave J., Tu L., Savale L., Huertas A., Humbert M. G.C. New insights in the pathogenesis of pulmonary arterial hypertension. Rev. Mal. Respir., 2019, vol. 36, no. 4, pp. 433-437. https://doi. org/10.1016/j.rmr.2019.03.003

15. Hamaoka-Okamoto A., Suzuki C., Yahata T., Ikeda K., Nagi-Miura N., Ohno N., Arai Yo., Tanaka H., Takamatsu T., Hamaoka K. The involvement of the vasa vasorum in the development of vasculitis in animal model of Kawasaki disease. Pediatric Rheumatology, 2014, vol. 12, no. 1, pp. 1-9. https://doi. org/10.1186/1546-0096-12-12

16. Boyle E. C., Haverich A. Microvasculature dysfunction as the common thread between atherosclerosis, Kawasaki disease, and severe acute respiratory syndrome coronavirus 2 (SARS-CoV-2)-associated multi-system inflammatory syndrome in children. European Journal of Cardio-Thoracic Surgery, 2020, vol. 58, no. 6, pp. 1109-1110. https://doi.org/10.1093/ejcts/ezaa367

17. Haverich A., Boyle E. C. Atherosclerosis, Pathogenesis and Microvascular Dysfunction. Springer, 2019.

18. McLaughlin R. F. (Jr), Tyler W. S., Canada R. O. Subgross Pulmonary Anatomy of the Rabbit, Rat, and Guinea Pig, with Additional Notes on the Human Lung. American Review of Respiratory Disease, 1965, vol. 94 , no. 4, pp. 380-387.

19. Ohtani O. Microvasculature of the rat lung as revealed by scanning electron microscopy of corrosion casts. Scanning electron microscopy, 1980, vol. 3, pp. 349-356.

20. Townsley M. I. Structure and composition of pulmonary arteries, capillaries and veins. Comprehensive Physiology, 2013, vol. 2, pp. 675-709. https://doi.org/10.1002/cphy.c100081

21. Suresh K. Lung Circulation. Comprehensive Physiology. 2020, vol. 6, no. 2, pp. 897-943. https://doi. org/10.1002/cphy.c140049

22. Clarke J. A. An X-Ray Microscopic Study of the Vasa Vasorum of Normal Human Pulmonary Arteries. Thorax, 1964, vol. 19, pp. 561-567. https://doi.org/10.1136/thx.19.6.561

23. Clarke J.A. An X-ray microscopic study of the vasa vasorum of the normal human pulmonary trunk. Acta Anat., 1965, vol. 61, no. 1, pp. 6-14. https://doi.org/10.1159/000142680 
24. Heath D., Smith P., Gosney J., Mulcahy D., Fox K., Yacoub M., Harris P. The pathology of the early and late stages of primary pulmonary hypertension. Heart, 1987, vol. 58, no. 3, pp. 204-213. https://doi. org/10.1136/hrt.58.3.204

25. Rosenkranz S., Gibbs J. S. R., Wachter R., de Marco T., Vonk-Noordegraaf A., Vachiéry J.L. Left ventricular heart failure and pulmonary hypertension. European Heart Journal, 2016, vol. 37, no. 12, pp. 942-954. https://doi.org/10.1093/eurheartj/ehv512

26. Dunham-Snary K. J., Wu D., Sykes E. A, Thakrar A., Parlow L. R. G., Mewburn J. D., Parlow J. L., Archer S. L. Hypoxic Pulmonary Vasoconstriction: From Molecular Mechanisms to Medicine. Chest, 2017, vol. 151, no. 1, pp. 181-192. https://doi.org/10.1016/j.chest.2016.09.001

27. Euler U.S. V., Liljestrand G. Observations on the Pulmonary Arterial Blood Pressure in the Cat. Acta Physiologica Scandinavica, 1946, vol. 12, no. 4, pp. 301-320. https://doi.org/10.1111/j.1748-1716.1946. tb00389.X

28. Stroev Y.I., Churilov L.P. Diagnosis of the diseases of respiratory system and its pathophysiological basis: iii. Cor pulmonale - pulmonary heart disease. Rus. Biomed. Res., 2020, vol. 5, no. 2, pp. 4-16.

29. Zaichik A.S., Churilov L.P. Inflammatory Foci Autonomy, Autochthonous Character and Barrier Functions of Inflammation. Osnovy obschej patologii. ELBI-SpezLit Publishers, 1999. 654 p. (In Russian)

30. Yuan X. J., Goldman W.F., Tod M. L., Rubin L. J., Blaustein M.P. Hypoxia reduces potassium currents in cultured rat pulmonary but not mesenteric arterial myocytes. American Journal of Physiology Lung Cellular and Molecular Physiology, 1993, vol. 264 (2 Pt 1), L107-15. https://doi.org/10.1152/ ajplung.1993.264.2.1116

31. Goldenberg N.M., Wang L., Ranke H., Liedtke W., Tabuchi A.K.W. TRPV4 Is Required for Hypoxic Pulmonary Vasoconstriction. Anesthesiology, 2015, vol. 122, no. 6, pp. 1338-1348. https://doi. org/10.1097/ALN.0000000000000647

32. Wang L., Yin J., Nickles H.T., Ranke H., Tabuchi A., Hoffmann Ju., Tabeling C., Barbosa-Sicard E., Chanson M., Kwak B.R., Shin H.-S., Wu S., Isakson B.E., Witzenrath M., de Wit C., Fleming I., Kuppe H., Kuebler W.M. Hypoxic pulmonary vasoconstriction requires connexin 40-mediated endothelial signal conduction. Journal of Clinical Investigation, 2012, vol. 122, no. 11, pp. 4218-4230. https://doi.org/10.1172/JCI59176

33. Leong D., Rave R., Kocheril A., Sovari A.Cor Pulmonale Overview of Cor Pulmonale Management. Available at: https://emedicine.medscape.com/article/154062-overview (accessed: 01.02.2021).

34. Pietra G. G. Histopathology of primary pulmonary hypertension. Chest, 1994, vol. 105 (2 suppl.), 2S-6S. https://doi.org/10.1378/chest.105.2_Supplement.2S

35. Meyrick B., Perkett E. A. The sequence of cellular and hemodynamic changes of chronic pulmonary hypertension induced by hypoxia and other stimuli. The American review of respiratory disease, 1989, vol. 40, no. 5, pp. 1486-1489.

36. Zarins C. K., Giddens D. P., Bharadvaj B. K., Sottiurai V.S., Mabon R. F., Glagov S. Carotid bifurcation atherosclerosis. Quantitative correlation of plaque localization with flow velocity profiles and wall shear stress. Circulation Research, 1983, vol. 53, no. 4, pp. 502-514. https://doi.org/10.1161/01.RES.53.4.502

37. Fagundes A., Pereira A.H., Corrêa R.K., Oliveira M.T., Rodriguez R. Efeitos da remoção da túnica adventícia da aorta descendente em suínos. Revista do Colégio Brasileiro de Cirurgiões, 2012, vol. 39, no. 2, pp. 133-138. https://doi.org/10.1590/S0100-69912012000200009

38. Sobin S. S., Frasher W. G., Tremer H. M. Vasa vasorum of the pulmonary artery of the rabbit. Circulation research, 1962, vol. 11, pp. 257-263. https://doi.org/10.1161/01.RES.11.2.257

39. Heistad D. D., Armstrong M. L., Amundsen S. Blood flow through vasa vasorum in arteries and veins: Effects of luminal PO2. American Journal of Physiology - Heart and Circulatory Physiology, 1986, vol. 250, no. 3, pp. 434-442. https://doi.org/10.1152/ajpheart.1986.250.3.h434

40. Tanaka H., Zaima N., Sasaki T., Sano M., Yamamoto N., Saito T., Inuzuka K., Hayasaka T., Goto-Inoue N., Sugiura Yu., Sato K., Kugo H., Moriyama T., Konno H., Setou M., Unno N. Hypoperfusion of the Adventitial Vasa Vasorum Develops an Abdominal Aortic Aneurysm. Cheng X, ed. PloS One, 2015, vol. 10, no. 8, e0134386. https://doi.org/10.1371/journal.pone.0134386

41. Fagundes A., Pereira A.H., Corrêa R.K., de Oliveira M.T., Rodriguez R. Effects of removal of the adventitia of the descending aorta and structural alterations in the tunica media in pigs. Revista do Colegio Brasileiro de Cirurgioes, 2012, vol. 39, no. 2, pp. 133-137. https://doi.org/10.1590/S010069912012000200009

42. Heistad D. D., Armstrong M. L., Amundsen S. Blood flow through vasa vasorum in arteries and veins: Effects of luminal PO2. American Journal of Physiology - Heart and Circulatory Physiology, 1986, vol. 250, no. 3, pp. 434-442. https://doi.org/10.1152/ajpheart.1986.250.3.h434 
43. Barker S. G., Causton B. E., Baskerville P. A., Gent S., Martin J.F. The vasa vasorum of the rabbit carotid artery. J. Anat., 1992, vol. 180, pp. 225-231.

44. Martin J. F, Booth R.F MS. Arterial wall hypoxia following hyperfusion through the vasa vasorum is an initial lesion in atherosclerosis. Eur. J. Clin. Invest., 1990, vol. 20, no. 6, pp. 588-592. https://doi. org $/ 0.1111 / \mathrm{j}$

45. Umar S., Ruffenach G., Moazeni S., Vaillancourt M., Hong J., Cunningham Ch., Cao N., Navab S., Sarji Sh., Li Min, Lee L., Fishbein G., Ardehali A., Navab M., Reddy S., Eghbali M. Involvement of Low-Density Lipoprotein Receptor in the Pathogenesis of Pulmonary Hypertension. Journal of the American Heart Association, 2020, vol. 9, no. 2, e012063. https://doi.org/10.1161/JAHA.119.012063

46. Pirillo A. LOX-1, OxLDL and Atherosclerosis. Mediators of Inflammation, 2013, vol. 2013 (March). 12 p.

47. Petroglou D., Kanellos I., Savopoulos C., Kaiafa G., Chrysochoou A., Skantzis P., Daios S., Hatzitolios A. I., Giannoglou G. The LDL-Receptor and its Molecular Properties: From Theory to Novel Biochemical and Pharmacological Approaches in Reducing LDL-cholesterol. Curr. Med. Chem., 2020, vol. 27, no. 2, pp. 317-333. https://doi.org/10.2174/0929867325666180604114819

48. Ellulu M. S., Patimah I., Khaza’ai H., Rahmat A., Abed Y., Ali F. Atherosclerotic cardiovascular disease: a review of initiators and protective factors. Inflammopharmacology, 2016, vol. 24, no. 1, pp. 1-10. https://doi.org/10.1007/s10787-015-0255-y

49. Szekanecz Z., Kerekes G., Végh E., Kardos Z., Baráth Z., Tamási L., Shoenfeld Y. Autoimmune atherosclerosis in 3D: How it develops, how to diagnose and what to do. Autoimmun Rev., 2016, vol. 15, no. 7, pp. 756-769. https://doi.org/10.1016/j.autrev.2016.03.014

50. Gerö S. Some data on the influence of cholesterol atherosclerosis by immunological means. Rev. Atheroscler. (Paris), 1967, vol. 9, no. 1, pp. 194-198.

51. Cinoku I. I., Mavragani C.P., Moutsopoulos H.M. Atherosclerosis: Beyond the lipid storage hypothesis. The role of autoimmnity. European Journal of Clinical Investigation, 2020, vol. 50, no. 2, pp. 1-9. https://doi.org/10.1111/eci.13195

52. Sanjadi M., Rezvanie Sichanie Z., Totonchi H., Karami J., Rezaei R., Aslani S. Atherosclerosis and autoimmunity: a growing relationship. International Journal of Rheumatic Diseases, 2018, vol. 21, no. 5, pp. 908-921. https://doi.org/10.1111/1756-185X.13309

53. Marasini B., Massarotti M., Cossutta R., Massironi L., Mantero A. Pulmonary hypertension in autoimmune rheumatic diseases. Reumatismo, 2005, vol. 57, no. 2, pp. 114-118. https://doi.org/10.4081/ reumatismo.2005.114

54. Gorbachev V.P. Changes in the pulmonary artery in collagen diseases. Arkh. Patol., 1979, vol. 41, no. 2, pp. 31-35. (In Russian)

55. Sugimoto K., Nakazato K., Sato A., Suzuki S., Yoshihisa A., Machida T., Saitoh S., Sekine H., Takeishi Ya. Autoimmune disease mouse model exhibits pulmonary arterial hypertension. PLoS ONE, 2017, vol. 12, no. 9, pp. 2-13. https://doi.org/10.1371/journal.pone.0184990

56. Moore G. W., Smith R.R.H.G. Pulmonary artery atherosclerosis: correlation with systemic atherosclerosis and hypertensive pulmonary vascular disease. Arch. Pathol. Lab. Med., 1982, vol. 106, no. 8, pp. 378-380.

57. Kohnken R., Scansen B. A., Premanandan C. Vasa Vasorum Arteriopathy: Relationship with Systemic Arterial Hypertension and Other Vascular Lesions in Cats. Veterinary Pathology, 2017, vol. 54, no. 3, pp. 475-483. https://doi.org/10.1177/0300985816685137

58. Moschcowitz E. Hyperplastic arteriosclerosis versus atherosclerosis. J. Am. Med. Assoc., 1950, vol. 143, no. 10, pp. 861-865. https://doi.org/10.1001/jama.1950.02910450001001

59. Fishbein M. C., Fishbein G. A. Arteriosclerosis: facts and fancy. Cardiovasc. Pathol., 2015, vol. 24, no. 6, pp. 335-342. https://doi.org/10.1016/j.carpath.2015.07.007

Received: February 26, 2021 Accepted: March 25, 2021

Authors' information:

Emma L.Heise - Doctoral Student; emma-.1.heise@gmail.com

Leonid P. Churilov - MD, PhD in Medicine, Associate Professor, Full Member of the International Academy of Sciences (Health and Ecology); elpach@mail.ru

Tatiana A. Novitskaya - MD, PhD in Medicine, Associate Professor; nta0666@rabmler.ru

Piotr K. Yablonsky - MD, Dr. Sci. in Medicine, Full Professor; p.yablonskii@spbu.ru

Axel Haverich - Dr. Sci. in Medicine, Professor, Foreign Corr. Member

of the Russian Academy of Sciences; haverich.axel@mh-hannover.de 